\title{
Protective effect of Sam-Hwang-Sa-Sim-Tang against hepatic steatosis in mice fed a high-cholesterol diet
}

\author{
Tae-Gue Ahn', Joo-Young Lee ${ }^{2}$, Se-Yun Cheon ${ }^{1}$, Hyo-Jin An ${ }^{1}$ and Yoon-Bum Kook ${ }^{2^{*}}$
}

\begin{abstract}
Background: Sam-Hwang-Sa-Sim-Tang (SHSST) is a traditional Oriental medication that has been commonly used in Korea for the treatment of hypertension, insomnia, and chest pain. In addition, some studies reported that administration of SHSST results suppression of hyperlipidemia in rats or lowering lipid plasma level such as total cholesterol (TC). Those results made us find and demonstrate positive effect of SHSST much more. The aim of the current study was to examine whether SHSST exerts an effect against hepatic steatosis and two type of SHSST has different efficacy on liver steatosis.
\end{abstract}

Methods: Total 40 mice were divided randomly and equally into 4 groups: a normal diet (CON) group, highcholesterol diet (HC) group, and treatment groups fed a high-cholesterol diet (HCD) with a 30\% or 80\% ethanol extract of SHSST (SHSST-L and SHSST-H, respectively). The HCD was given for 9 weeks. The SHSST-treated groups were orally administered SHSST at a dose of $150 \mathrm{mg} / \mathrm{kg}$, whereas the other groups received physiological saline.

Results: SHSST administration to mice resulted in a decline in serum levels of total cholesterol and low-density lipoprotein. Histological examination showed that lipid droplets were smaller in the SHSST-treated group than in the $\mathrm{HC}$ group. At the protein level, expression of sterol regulatory element-binding protein 2 (SREBP-2) was suppressed by SHSST. In addition, the mRNA expression of cholesterol metabolism-related molecules such as SREBP-2, liver $X$ receptor (LXR), low-density lipoprotein receptor (LDLR), and 3-hydroxy-3methylglutary-CoA (HMG-COA) was also suppressed in SHSST-treated groups in the liver. In the aorta tissue, SHSST decreased the expression of tumor necrosis factor-a (TNF-a), interleukin-6 (IL-6), intercellular adhesion molecule-1 (ICAM-1), vascular cell adhesion molecule-1(VCAM-1), transforming growth factor (TGF)- $\beta 1$, and fibronectin.

Conclusions: The present study indicates that SHSST protects against liver steatosis and protects vessels against inflammation arising from excessive ingestion of cholesterol. These findings may also suggest that SHSST could be used as an adjuvant remedy for protection against liver steatosis.

Keywords: Sam-Hwang-Sa-Sim-Tang (SHSST), Liver steatsosis, High-cholesterol diet (HCD)

\section{Background}

Metabolic syndrome is a group of conditions that increase the risk of diabetes, cardiovascular diseases, and carcinogenesis [1]. Genetic and environmental factors are considered to promote the development of metabolic syndrome. In addition, obesity, diabetes, and nonalcoholic fatty liver disease (NAFLD) are common in

\footnotetext{
*Correspondence: kook@sj.ac.kr

${ }^{2}$ Department of Presctiption, College of Oriental Medicine, Sangji University, Wonju-si, Gangwon-do 220-702, Republic of Korea

Full list of author information is available at the end of the article
}

metabolic syndrome [2,3]. NAFLD frequently causes abnormal liver function, and one of the characteristic features of NAFLD is hepatic steatosis [4]. The role of dietary cholesterol, with the subsequent increased hepatic esterification of cholesterol and its association to hepatic triglyceride accumulation, is a new paradigm for hepatic steatosis [5]. Although hepatic steatosis can proceed to end-stage liver disease, ideal treatment for this disease has not yet been established. Therefore, prevention of hepatic steatosis may be useful for populations at risk of advanced liver disease [6,7].

\section{Biomed Central}


Sam-Hwang-Sa-Sim-Tang (SHSST) is composed of 3 herbs; Coptidis rhizoma of the Ranunculaceae family (rhizomes of Coptis chinensis; CC), Scutellariae radix of the Labiatae family (roots of Scutellaria baicalensis; SB), and Rhei rhizoma of the Polygonaceae family (rhizomes of Rheum officinale; RO). In traditional Korean medicine, SHSST has been commonly prescribed for hypertension, insomnia, and chest pain [8-10]. Recent studies have also reported various beneficial effects of SHSST, including anti-inflammatory, antihypertensive, antiatherogenic, and antioxidant effects [11-14]. In addition, there were studies that reported SHSST-administrated rats showed the tendency of decline of several lipid plasma levels including total cholesterol and administration of SHSST suppressed the development of hyperlipememia $[10,11]$. Generally, liver is considered as central organ in lipid metabolism $[15,16]$. Therefore, those previous studies made us think SHSST might show those positive effects because of some positive connection with metabolic role of liver. Plus, several studies have suggested that the efficacy of herbs could differ depending on the type of solvent, e.g., water, methanol, or ethanol, or the concentration of solvent used to extract the active ingredient [17-20].

Taking into all those facts account, we decided to study the positive effect of SHSST related with lipid metabolism specifically in liver. We finally hypothesized that SHSST might have a protective effect against hepatic steatosis induced by a high-cholesterol diet (HCD) because hepatic steatosis induced by HCD is basic features of NAFLD and it is also one of general pathological status closely related with lipid metabolism. In addition, we also hypothesized the efficacy of SHSST against hepatic steatosis may differ depending on the concentration of ethanol used to extract active ingredients from SHSST. In addition, because the protective effect of SHSST against hepatic steatosis is not known, we decided to study the effects of SHSST in mice with hepatic steatosis induced by HCD. To our knowledge, this is the first study to evaluate the efficacy of SHSST against liver steatosis according to the concentration of ethanol used for extraction of SHSST.

\section{Methods}

\section{Reagents}

CF, SG, and RB were purchased from Omniherb Co. Ltd (Daegu, Republic of Korea). The normal diet and HCD were obtained from Research Diets (New Brunswick, NJ, USA). The other reagents were purchased from SigmaAldrich (St. Louis, MO, USA), unless otherwise specified in the text.

\section{Preparation of SHSST}

SHSST consists of CC, SB, and RO. Each herb was used in a ratio of 1:1:1 (300 g: $300 \mathrm{~g}: 300 \mathrm{~g})$. The herbs had a moisture content of $<11 \%$ by weight and were air-dried. The combination of herbs was subjected to extraction with $30 \%$ or $80 \%(\mathrm{v} / \mathrm{v})$ ethanol in water at $60^{\circ} \mathrm{C}$ for $8 \mathrm{~h}$. The extracts were filtered with $10 \mu \mathrm{M}$ cartridge paper, and the ethanol was removed via vacuum rotary evaporation (Eyela, Japan). The concentrates were freeze-dried, and the yields were $13 \%$ and $15 \%$ for the $30 \%$ and $80 \%$ ethanol extracts, respectively. The powders were dissolved in distilled water for the experiments, and the residual powders were stored at $-20^{\circ} \mathrm{C}$.

\section{Animal experiments}

Forty male C57BL/6 J mice weighing 18-19 g at the age of 3 weeks were purchased from Daehan Biolink (Daejeon, Republic of Korea). The animals were all maintained in accordance with conditions recommended according to the National Institutes of Health guidelines. The Institutional Animal Care Committee of Sangji University is according to the NIH guidelines. This study was submitted recommended by the Institutional Animal Care Committee of Sangji University (reg. no. 2012-3). The mice were adapted to the feeding conditions for 2 weeks. They were then given free access to food and tap water for 9 weeks and were housed under a $12 \mathrm{~h}$ light/dark cycle at a constant temperature of $22^{\circ} \mathrm{C} \pm 2{ }^{\circ} \mathrm{C}$ and relative humidity of $55 \% \pm 10 \%$. The mice were randomly separated into 6 groups of 10 mice each: the normal diet (CON) group, HCD (HC) group, and treatment groups fed HCD with the $30 \%$ or $80 \%$ ethanol extract of SHSST (L and H, respectively). Mice except CON group consumed HCD (D12108; Research Diets Inc., New Brunswick, New Jersey, USA) containing $20.1 \%$ saturated fat, $1.37 \%$ cholesterol, and $0 \%$ sodium cholate. The SHSST-treated groups were orally administered with SHSST at a dose of $150 \mathrm{mg} /$ $\mathrm{kg}$. The other groups were administered the same volume of physiological saline. Body weight and dietary intake were recorded every week. At the end of this period, the animals were fasted overnight. The following day, they were anesthetized with Zoletil (Virbac, Carros Cedex, France), and blood samples were then collected by cardiac puncture. The liver and aorta tissue were then excised, rinsed, weighed, and directly stored at $-80^{\circ} \mathrm{C}$ until analysis.

\section{Serum analysis}

Serum concentrations of total cholesterol (TC), lowdensity lipoprotein (LDL), alanine aminotransferase (ALT), and blood urea nitrogen (BUN) were determined by enzymatic methods with commercial kits (Biovision Research Products, Inc., CA, USA).

\section{Histological analysis}

Livers from representative mice in each group were fixed in $10 \%$ buffered formalin, embedded in paraffin, and cut 
Table 1 Primer sequences and PCR conditions

\begin{tabular}{|c|c|c|c|}
\hline Gene name & $\operatorname{Tm}\left({ }^{\circ} \mathrm{C}\right)$ & Size (bp) & Sequence $5^{\prime}-3^{\prime}$ \\
\hline Sterol regulatory element binding transcription factor 2 & 55 & 177 & F: GGCCTCTCCTTTAACCCCTT \\
\hline (SREBP2) & & & R: CACCATTTACCAGCCACAGG \\
\hline Liver $X$ receptor & 55 & 119 & F: TCCTACACGAGGATCAAGCG \\
\hline$(L X R)$ & & & R: AGTCGCAATGCAAAGACCTG \\
\hline Low density lipoprotein receptor & 55 & 173 & F: GCGTATCTGTGGCTGACACC \\
\hline$(\mathrm{LDLR})$ & & & R: TGTCCACACCATTCAAACCC \\
\hline 3-hydroxy-3methylglutary-CoA & 55 & 151 & F: GTGGCAGAAAGAGGGAAAGG \\
\hline$(\mathrm{HMG}-\mathrm{COA})$ & & & R: CGCCTITGTITCTGGTTGA \\
\hline Tumor necrosis factor alpha & 55 & 275 & F: AACATCCAACCTTCCCAAACG \\
\hline (TNFa) & & & R: GACCCTAAGCCCCCAATTCTC \\
\hline Interleukin 6 & 55 & 162 & F: TTGCCTTCTTGGGACTGATG \\
\hline$(\mid \mathrm{L}-6)$ & & & R: CCACGATTTCCCAGAGAACA \\
\hline Intercelluar adhesion molecule 1 & 55 & 176 & F: GTGGGTCGAAGGTGGTTCTT \\
\hline (ICAM1) & & & R: GCAGTTCCAGGGTCTGGTTT \\
\hline Vascular cell adhesion molecule 1 & 55 & 163 & F: CTCAGGTGGCTGCACAAGTT \\
\hline (VCAM1) & & & R: AGAGCTCAACACAAGCGTGG \\
\hline Transforming growth factor beta1 & 55 & 169 & F: GCGGCAGCTGTACATTGACT \\
\hline$(T N F \beta)$ & & & R: CCGGGTTGTGTTGGTTGTAG \\
\hline Fibronectin 1 & 55 & 197 & F: AGCTITTCCCTGCACCTGAT \\
\hline & & & R: GGTGGGTGTCACCTGACTGA \\
\hline
\end{tabular}

into 8 - $\mu \mathrm{m}$-thick sections. Some sections were then stained with hematoxylin and eosin (H\&E) for histological examination of fat droplets. Images were acquired using an SZX10 microscope (Olympus, Tokyo, Japan).

\section{Western blot}

The liver tissues were homogenized in commercial lysis buffer PRO-PREP ${ }^{\circledR}$ (Intron Biotechnology Inc, Gyeongido, Republic of Korea) and then incubated for $25 \mathrm{~min}$ on ice to induce cell lysis. The samples were centrifuged

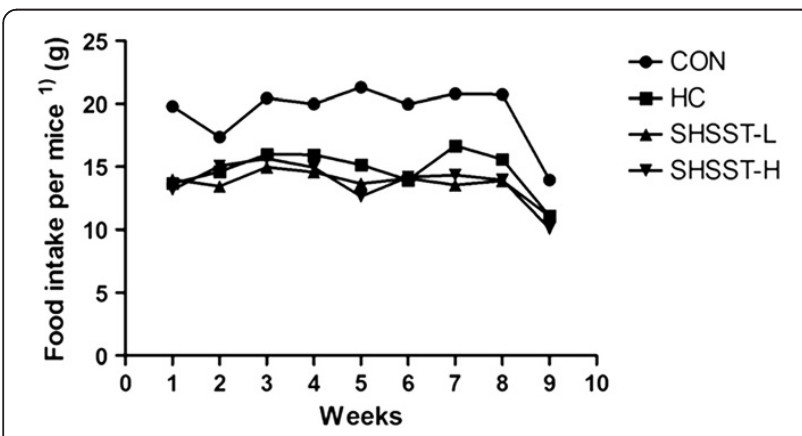

Figure 1 Effects of SHSST on food intake. Values have been expressed for 10 mice per group. ${ }^{11}$ Food intake per mouse = amount of total food intake in each group $(\mathrm{g}) /$ number of mice in each group. at $13,000 \mathrm{rpm}\left(4^{\circ} \mathrm{C}\right)$ for $5 \mathrm{~min}$, and the supernatant was transferred to a new $1.5 \mathrm{~mL}$ tube. The protein concentration was determined using the Bio-Rad protein assay reagent according to the manufacturer's instructions (Bio-Rad, Hercules, CA, USA). Protein samples $(16 \mu \mathrm{g})$ were electroblotted onto a poly-vinyl difluoride (PVDF) membrane following separation on a $10 \%$ sodium dodecyl sulfate (SDS)-polyacrylamide gel. Membranes were blocked with a $5 \%$ skim milk solution at $4^{\circ} \mathrm{C}$ for $1 \mathrm{~h}$. The membranes were incubated overnight with anti-SREBP-2 (Santa Cruz, CA, USA) as the primary antibody. Blots were washed 3 times with Tween 20/Tris-buffered saline (TTBS). After the blots were incubated with the corresponding secondary antibody (Santa Cruz, CA, USA) for $1 \mathrm{~h}$ at room temperature, they were washed 3 times with TTBS and were then developed using enhanced chemiluminescence (ECL) on X-ray film (Amersham Life Science, Buckinghamshire, UK).

Table 2 Body weights (g) at starting week and final week respectively

\begin{tabular}{lcccc}
\hline & CON & HC & SHSST-L & SHSST-H \\
\hline Start week (0) & $22.49 \pm 1.08$ & $22.13 \pm 0.95$ & $22.72 \pm 1.37$ & $22.9 \pm 1.09$ \\
Final week (9) & $25.75 \pm 1.12$ & $25.7 \pm 1.12$ & $23.76 \pm 2.22$ & $23.7 \pm 0.92$
\end{tabular}

Values have been expressed as the mean \pm SEM values of 10 mice per group. 


\section{Real-time polymerase chain reaction (PCR) analysis}

Each liver and aorta sample was homogenized, and total RNA was isolated using the Easy-Blue ${ }^{\bullet}$ Reagent (Intron Biotechnology Inc, Gyeongi-do, Republic of Korea) according to the manufacturer's instructions. Total RNA was quantified using an Epoch ${ }^{\bullet}$ micro-volume spectrophotometer system (BioTek Instruments, Inc. Winooski, VT, USA). In brief, total RNA from the liver and aorta samples was converted to cDNA by using a highcapacity cDNA reverse transcription kit (Applied Biosystems, Foster City, CA, USA). Reverse transcription was conducted in a thermocycler (Gene Amp ${ }^{\oplus}$ PCR system 9700, Applied Biosystems) with the following program: initiation for $10 \mathrm{~min}$ at $25^{\circ} \mathrm{C}$, followed by incubation at $50^{\circ} \mathrm{C}$ for $90 \mathrm{~min}$ and at $85^{\circ} \mathrm{C}$ for $5 \mathrm{~min}$. The cDNA synthesized was then stored at $-20^{\circ} \mathrm{C}$. Real-time PCR analysis was conducted using a Step One Plus ${ }^{\bullet}$ Real-time PCR system (Applied Biosystems). SYBR ${ }^{\odot}$ Green master mix and primers were used for PCR analysis of glyceraldehyde-3phosphate dehydrogenase (GAPDH), sterol regulatory element-binding protein 2 (SREBP-2), liver $\mathrm{X}$ receptor (LXR), low-density lipoprotein receptor (LDLR), and 3hydroxy-3methylglutary-CoA (HMG-CoA) in liver tissue and for GAPDH, tumor necrosis factor- $\alpha$ (TNF- $\alpha$ ), interleukin-6 (IL-6), intercellular adhesion molecule-1

(A)

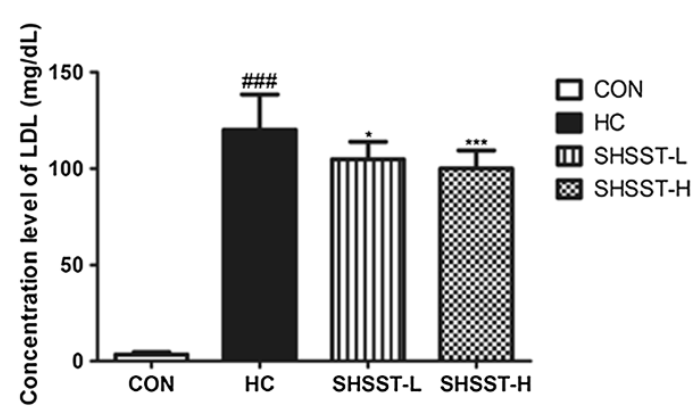

(B)

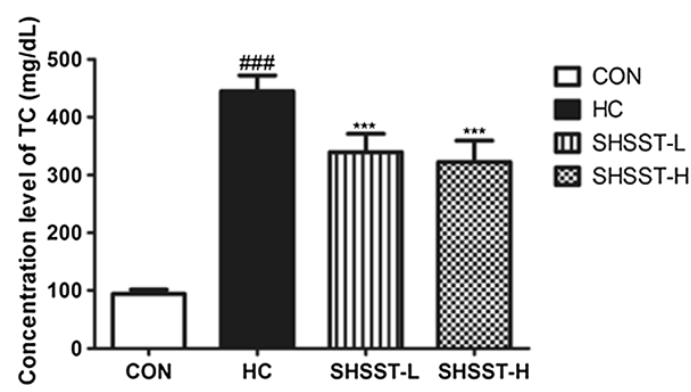

Figure 2 Effects of SHSST on LDL and TC in experimental mice. (A) Serum level of LDL (B) Serum level of TC, CON, standard diet group; HC, high cholesterol diet group; SHSST-L, HC plus $30 \%$ ethanol extract of SHSST treatment group, SHSST-H, HC plus $80 \%$ ethanol extract of SHSST treatment group. Values have been expressed as the mean \pm SEM values of 10 mice per group. ${ }^{\# \#} p<0.001$ vs. CON group. ${ }^{*} p<0.05$ vs. HC group, ${ }^{* * *} p<0.001$ vs. HC group.
(ICAM-1), vascular cell adhesion molecule-1(VCAM-1), transforming growth factor (TGF)- $\beta 1$, and fibronectin in aorta tissue (Santa Cruz, CA, USA). The PCR cycling parameters were as follows: $10 \mathrm{~min}$ at $95^{\circ} \mathrm{C} ; 40$ cycles of $5 \mathrm{~s}$ at $95^{\circ} \mathrm{C}$ and $45 \mathrm{~s}$ at $60^{\circ} \mathrm{C}$; and a final melting curve of $15 \mathrm{~s}$ at $95^{\circ} \mathrm{C}, 1 \mathrm{~min}$ at $60^{\circ} \mathrm{C}$, and $15 \mathrm{~s}$ at $95^{\circ} \mathrm{C}$. All primer sequences and annealing temperatures are shown in Table 1. Gene expression was calculated according to the comparative threshold cycle $(\mathrm{Ct})$ method (Applied Biosystems).

\section{Statistical analysis}

All the values reported have been expressed as the mean \pm SEM values for 10 mice. Data were analyzed using oneway analysis of variance (ANOVA) with Dunnett's test. Statistical analysis was performed using GraphPad Prism (version 5).

\section{Results}

\section{Effects of SHSST on body weight and food intake}

Figure 1 shows the food intake of each group. There were no significant differences between the HC group and the SHSST-treated group with regard to food intake. Table 2 shows the total body weight of mice at the

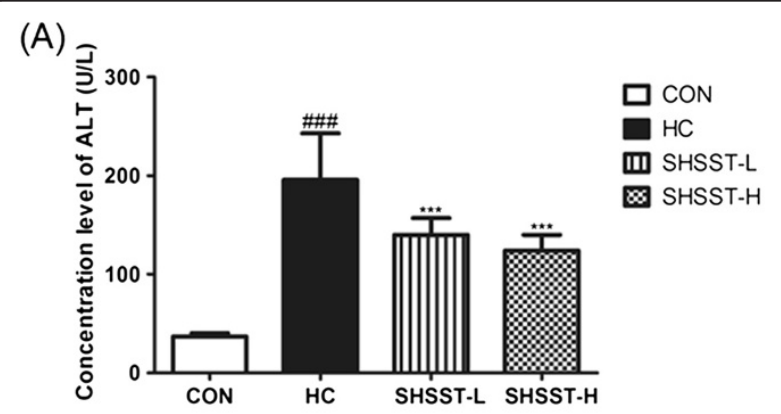

(B)

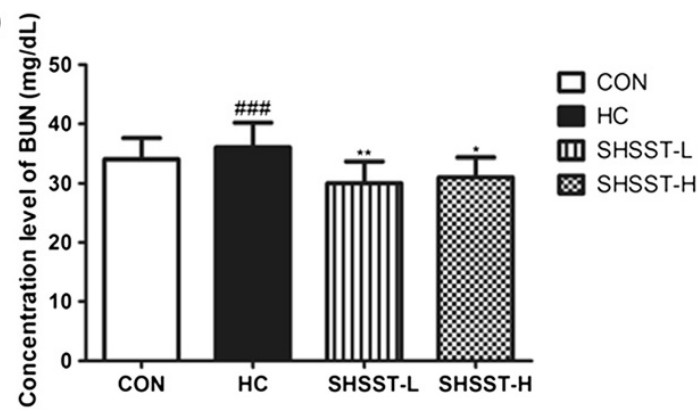

Figure 3 Effects of SHSST on ALT and BUN in experimental mice. (A) Serum level of ALT (B) Serum level of BUN. CON, standard diet group; HC, high-cholesterol diet group; SHSST-L, HC plus 30\% ethanol extract of SHSST treatment group; SHSST-H, HC plus $80 \%$ ethanol extract of SHSST treatment group. Values have been expressed as the mean \pm SEM values of 10 mice per group. ${ }^{\# \#} p<$ 0.001 vs. CON group. ${ }^{*} p<0.05$ vs. HC group, . ${ }^{* *} p<0.01$ vs. HC group, ${ }^{* * *} p<0.001$ vs. HC group. 
starting and final points of the experiments. Although the average body weight of each group was almost the same at the starting point, the body weights in the SHSST-treated group were slightly lower than those in the $\mathrm{HC}$ group in the final week.

\section{Effects of SHSST on TC and LDL}

Figure 2 shows the concentrations of serum TC and LDL in each group. The concentrations of TC and LDL were higher in the $\mathrm{HC}$ group than in the other groups. Administration of SHST significantly suppressed elevation of the serum TC and LDL levels. In the SHSST-H group, although there was no statistical significance between the results for SHSST-L and SHSST-H, the TC and LDL levels were lower than those in the SHST-L group.

\section{Effects of SHSST on ALT and BUN}

The concentrations of ALT and BUN were higher in the $\mathrm{HC}$ group than in any of the other groups (Figure 3). In addition, the level of ALT in the SHSST-H group was lower than that in the SHSST-L group. In contrast, the level of BUN in the SHSST-L group was lower than that in the SHSST-H group. In particular, the level of BUN in the SHST-treated groups was slightly lower than that in the CON groups, although no statistically significant difference was observed between the SHSST-L group and SHSST-H group. In addition, all toxicity markers in the SHSST-treated group were within the normal range.

\section{Histological examinations}

Figure 3 shows the H\&E staining results for liver tissues from each group. In the $\mathrm{HC}$ group, lipid droplets appeared as small vacuoles within the liver cells near veins. Enlargement of lipid droplets in the liver tissue of mice in the $\mathrm{HC}$ group was more pronounced than that in the SHST-treated groups. Thus, the results for each representative tissue clearly showed that lipid accumulation in the liver was more considerable in the $\mathrm{HC}$ group than in the SHSST-L and SHSST-H groups.

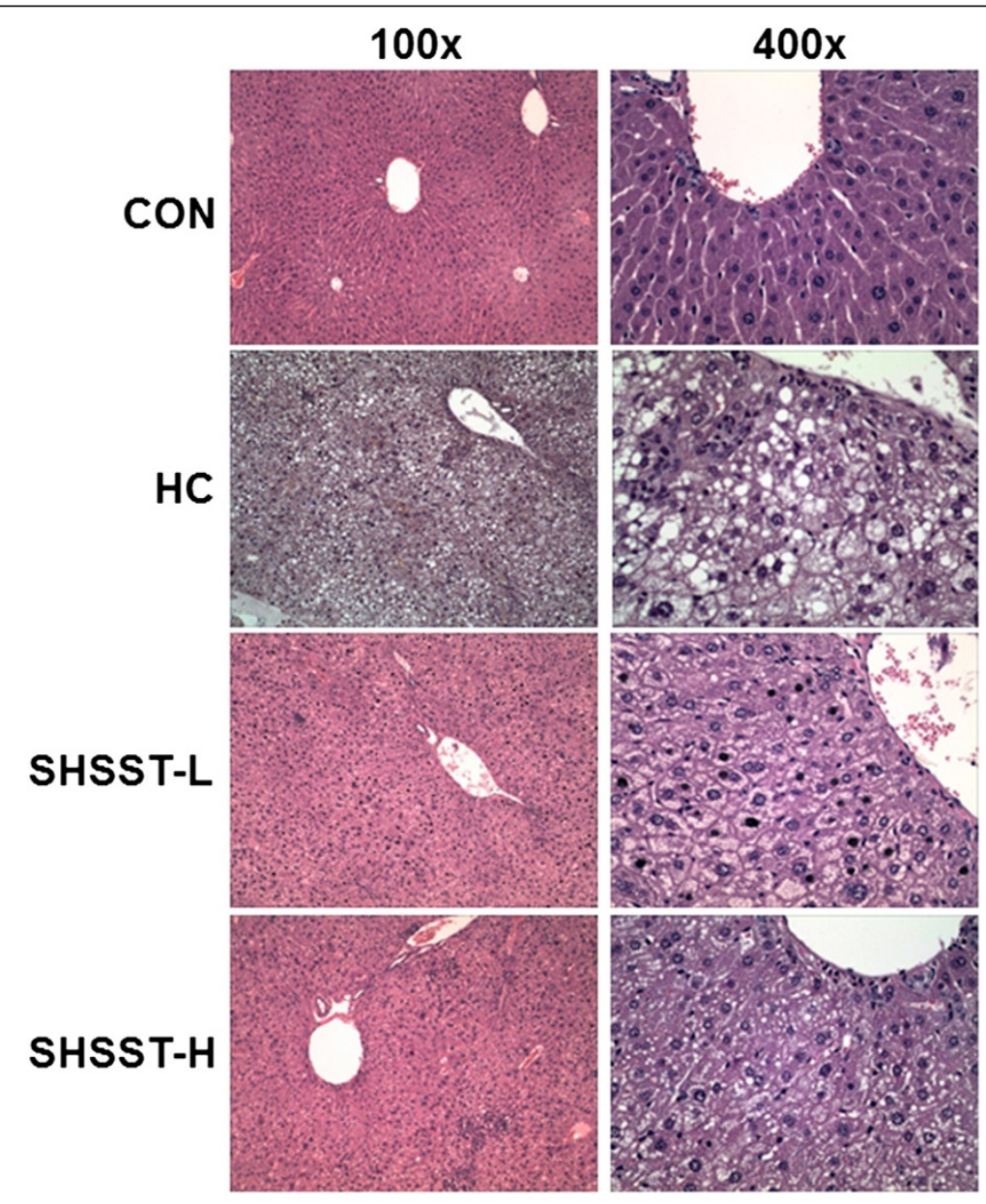

Figure 4 Effects of SHSST on representative H\&E staining of liver tissue. Pictures in the left panel are at the original magnification of 100X. The pictures in the right panel are at the original magnification of $400 \times$. 


\section{Effects of SHSST on liver tissue}

Figure 4 shows the results of western blot analysis. Protein expression of SREBP2, which is a key transcription factor involved in cholesterol homeostasis, was downregulated in the SHSST-treated group relative to that in the $\mathrm{HC}$ group. To determine whether the reduced amount of lipid droplets in SHSST-treated mice was associated with expression of hepatic genes involved in lipid and cholesterol metabolism, we examined the expression of SREBP2, LXR, LDLR, and HMG-CoA. In liver tissue, the mRNA expression of SREBP, LXR, LDLR, and HMGCoA was clearly lower in the STSST-treated groups than in the $\mathrm{HC}$ group (Figure 5). In addition, the expression of SREBP2, LXR, and LDLR in the SHSST-H group was lower than that in the SHSST-L group.

\section{Effects of SHSST on aorta tissue}

The mRNA expression of several molecules in aorta tissue is shown in Figure 6. In the HC group, the mRNA expression of all the molecules was higher than that in any other group, and SHSST administration significantly suppressed this elevation in mRNA expression. In addition, the mRNA expression of these molecules in the SHSST-H group tended to be lower than that in the SHSST-L group.

\section{Discussion}

NAFLD represents a histological spectrum of liver disease related to diabetes, insulin resistance, and obesity; this spectrum largely extends from isolated hepatic steatosis to steatohepatitis and cirrhosis. Hepatic steatosis is

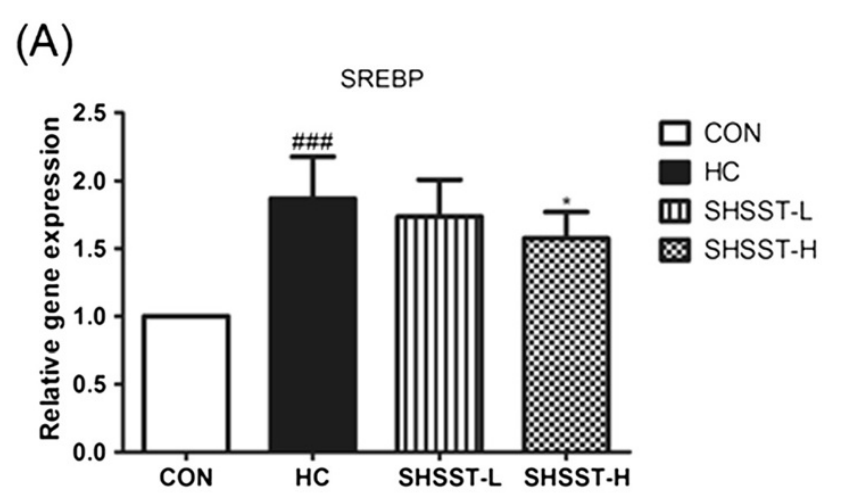

(B)

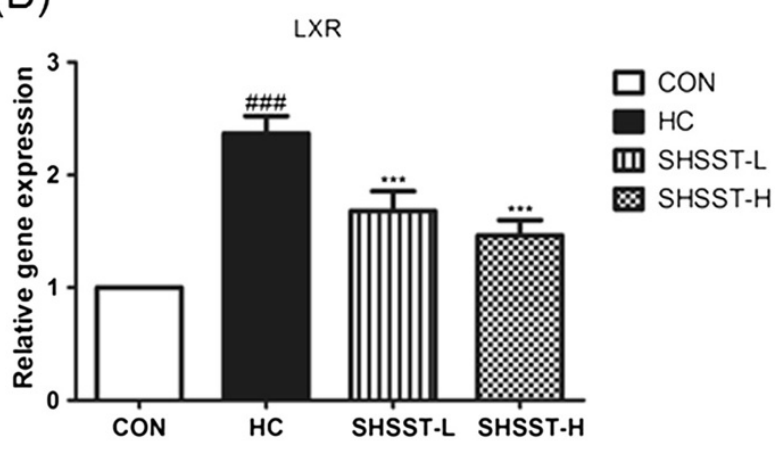

(C)

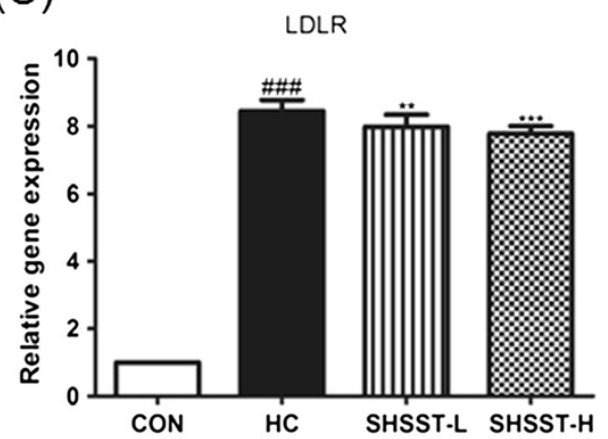

(D)
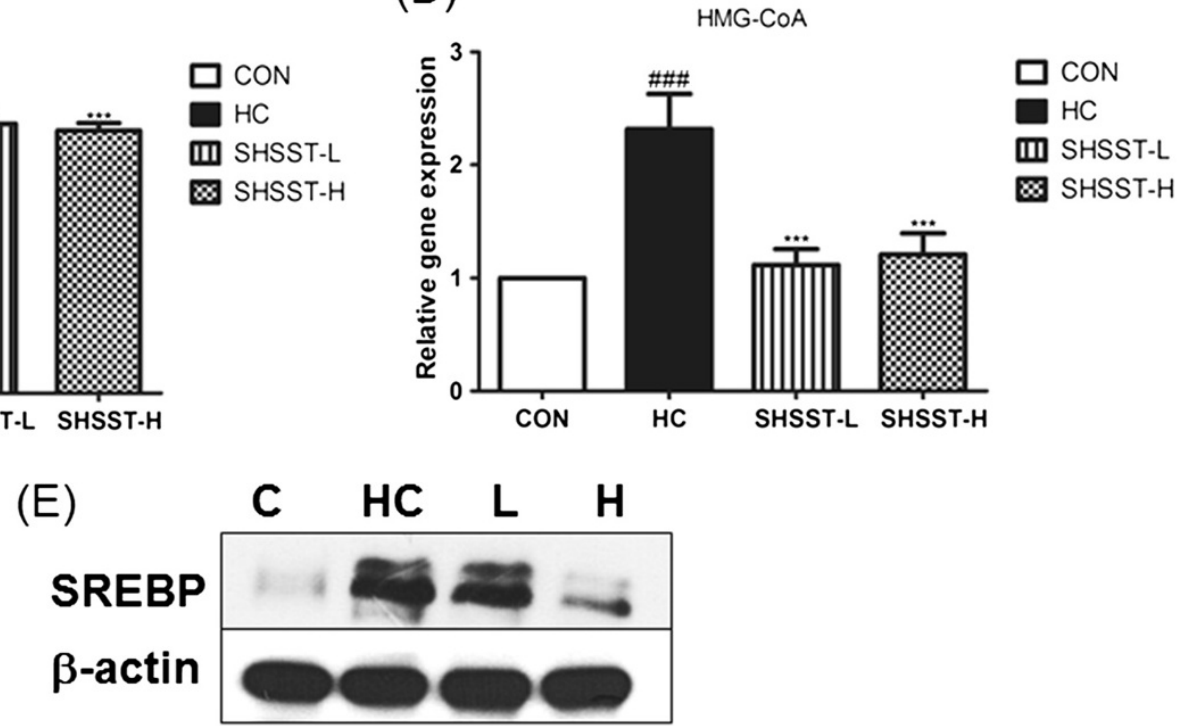

Figure 5 Effects of SHSST on liver tissue. (A) mRNA expression of SREBP-2, (B) LXR, (C) LDLR, and (D) HMG-CoA. (E) was Western bolt of SREBP-2. Data were normalized to GAPDH mRNA expression levels and then compared to the values for the CON group, which were assigned a value of 1.0. CON, standard diet group; HC, high-cholesterol diet group; SHSST-L, HC plus 30\% ethanol extract of SHSST treatment group; SHSST$\mathrm{H}, \mathrm{HC}$ plus $80 \%$ ethanol extract of SHSST treatment group. Each bar represents the mean \pm SEM value of 2 independent experiments for 10 mice from each group. ${ }^{\# \# \#} p<0.001$ vs. control group, ${ }^{*} p<0.05$ vs. HC group, ${ }^{* *} p<0.01$ vs. HC group, ${ }^{* * *} p<0.001$ vs. HC group. 


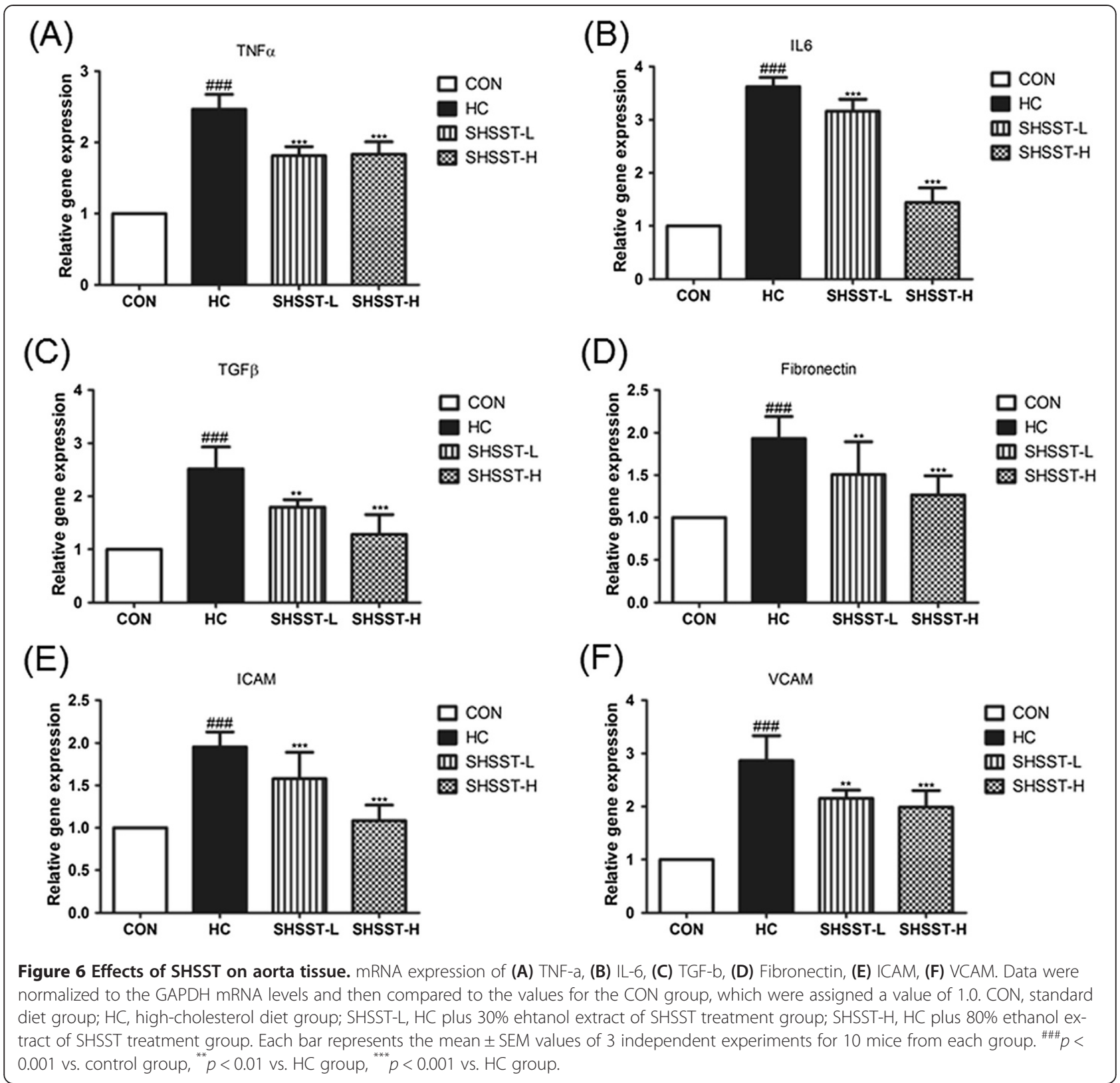

not only one feature of NAFLD but also both a potential cause of advanced liver disease and is also considered to be an important cofactor in the pathogenesis of various other liver diseases [21,22]. The development of hepatic steatosis is known to be closely associated with genetic and environmental factors [7,23,24].

The liver plays a central role in cholesterol and lipid metabolism [25]. It is widely assumed that cholesterol metabolism is governed by several hepatic genes, including SREBP-2, LXR, LDLR, and HMG-CoA [26,27]. In particular, members of the SREBP family such as SREBP1a, SREBP1c, and SREBP2 are key transcription factors that are known to control the production of lipids for export into the bile as micelles and into the serum as lipoproteins
[28]. Therefore, the protective effects of SHSST against liver steatosis may be studied by measuring suppressing of the expression of those several key hepatic transcription, especially SREBP-2.

Chronic intake of a high-fat diet has been reported to cause low-grade inflammation. In addition, excessive intake of cholesterol may cause vascular inflammation, and pro-inflammatory cytokines such as TNF- $\alpha$ and IL-6 may stimulate the expression of adhesion molecules and chemokines such as VCAM-1, ICAM-1, and fibronectin in aorta tissue [29-31]. VCAM-1 and ICAM-1 are thought to play an important role in the process of atherosclerosis by recruiting inflammatory cells, and they are both are upregulated by pro-atherogenic factors [31]. 
In the present study, we investigated the protective effect of SHSST against hepatic steatosis in mice with HCD-induced hepatic steatosis. We also used 2 different types of SHSST extracted using $30 \%$ and $80 \%$ ethanol to determine effects of extraction conditions on the efficacy of SHSST. The reason we decide to study effect of SHSST on hepatic steatosis specifically is simple and clear: as we had mentioned before, one of major factor causing NAFLD is over-substitution of high fat or high cholesterol. Though, NAFLD is a very comprehensive subject, hepatic steatosis is one of simple and basic features of NAFLD. To researchers, it means that demonstrating effect of SHSST on hepatic steatosis is more efficient way to demonstrate positive effect of SHSST related with lipid metabolism in liver specifically. That is why we decided to study SHSST in liver steatosis induced by HCD. SHSST has various active compounds, such as baicalein, baicalin, wogonin, and berberine. Baicalein has been reported that it can ameliorate obesity, dyslipidemia, fatty liver, and diabetes and insulin resistance [32]. Bak et al., reported Wogonin have beneficial effects on glucose and lipid metabolism related to enhanced PPAR $\alpha$ and adiponectin expression via AMPK activation [33]. Berberine has effects on NAFLD, diabetes, and hyperlipidemia [34]. We can suggest that these components from 3 herbs may be candidates against hepatic steatosis. The main compound for inhibiting hepatic steatosis has to investigate more.

In our study, SHSST clearly suppressed serum TC and LDL levels relative to those in the $\mathrm{HC}$ group. The protein levels of SREBP, a key transcription factor in cholesterol metabolism, were also lower in the SHSST-treated group than in the HC group. In addition, SHSST significantly inhibited the hepatic mRNA expression of several molecules such as SREBP-2, LXR, LDLR, and HMG-CoA that govern cholesterol metabolism, and it also suppressed the mRNA expression of TNF- $\alpha$, IL-6, VCAM-1, ICAM-1, and fibronectin in aorta tissue, relative to that in the $\mathrm{HC}$ group. These findings suggest that SHSST protected the liver from hepatic steatosis and aorta tissue from the initiation of atherosclerosis.

In our study, the SREBP-2 expression in protein level and mRNA expression of several molecules in the liver and aorta was inhibited to a greater extent in the SHSST$\mathrm{H}$ group than in the SHSST-L group, which suggests that the effective component of SHSST may be more efficiently extracted by using a high percentage of ethanol. It is interesting results. However, this is more than nothing but local observations and precise studies are needed to investigate the different pharmacological components between SHSST-L and SHSST-H. We expect that this issue might be solved in the near future.

The serum levels of ALT and BUN, which are specific toxicological markers, are enhanced in the case of liver injuries and kidney injuries, respectively $[35,36]$. In the present study, SHSST significantly decreased the increase in ALT and BUN levels, relative to those for the HC group. Thus, SHSST protected the liver and kidney from possible damage that could resulted from excessive intake of dietary cholesterol.

\section{Conclusions}

Our current investigation clearly demonstrates the protective effects of SHSST against hepatic steatosis by inhibiting the mRNA expression of key hepatic molecules such as SREBP-2, LXR, LDLR, and HMG-CoA. Our results also suggest that SHSST may suppress the initiation of atherosclerosis. These findings shed light on a possible preventative measure against liver steatosis.

\section{Competing interests}

The authors declare that they have no competing interests.

\section{Authors' contributions}

Conceived and designed the experiments: YBK. Performed the experiments: TGA, SYC, and JYL. Analyzed the data: HJA. Contributed reagents/materials/ analysis tools: HJA, and YBK. Wrote the paper: TGA and JYL. All authors read and approved the final manuscript.

\section{Acknowledgements}

This research was supported by Sangji University Research Fund, 2012.

\section{Author details}

${ }^{1}$ Department of Pharmacology, College of Oriental Medicine, Sangji University, Wonju-si, Gangwon-do 220-702, Republic of Korea. ${ }^{2}$ Department of Presctiption, College of Oriental Medicine, Sangji University, Wonju-si, Gangwon-do 220-702, Republic of Korea.

Received: 18 July 2013 Accepted: 28 November 2013

Published: 23 December 2013

\section{References}

1. Alberti KG, Zimmet $P$, Shaw J: The metabolic syndrome-a new worldwide definition. Lancet 2005, 366(9491):1059-1062.

2. Herrera BM, Keildson S, Lindgren CM: Genetics and epigenetics of obesity. Maturitas 2011, 69(1):41-49.

3. Marchesini G, Bugianesi E, Forlani G, Cerrelli F, Lenzi M, Manini R, Natale S, Vanni E, Villanova N, Melchionda N, et al: Nonalcoholic fatty liver, steatohepatitis, and the metabolic syndrome. Hepatology 2003, 37(4):917-923.

4. Kang JS, Lee WK, Lee CW, Yoon WK, Kim N, Park SK, Lee HS, Park HK, Han SB, Yun J, et al: Improvement of high-fat diet-induced obesity by a mixture of red grape extract, soy isoflavone and L-carnitine: implications in cardiovascular and non-alcoholic fatty liver diseases. Food Chem Toxicol 2011, 49(9):2453-2458.

5. Kim E, Choi $Y$, Jang J, Park T: Carvacrol protects against hepatic steatosis in mice fed a high-fat diet by enhancing SIRT1-AMPK signaling. Evid Based Complement Altern Med: eCAM 2013, 2013:290104.

6. Wang JQ, Li J, Zou YH, Cheng WM, Lu C, Zhang L, Ge JF, Huang C, Jin Y, LV $X W$, et al: Preventive effects of total flavonoids of Litsea coreana leve on hepatic steatosis in rats fed with high fat diet. J Ethnopharmacol 2009, 121(1):54-60.

7. Angulo P, Lindor KD: Non-alcoholic fatty liver disease. J Gastroenterol Hepatol 2002, 17(Suppl):S186-S190.

8. Seok SH, Kim JH, Kim GW, Koo BS: A case of insomnia incurable by neuropsychiatric medication alone, but made possible with Sarn-HwangSa-Sim-Tang. J Orient Neuropsychiatry 2006, 17:117-129.

9. Kim JB, Kwon OK, Son CW, Shin HM: Vasodiatory effects of Samhwangsasim-tang on vascular smooth muscle. J Orient Physiol Pathol 2004, 18:1382-1386. 
10. Lee $\mathrm{JM}$, Lee E: Antihyperlipidemic and antioxidant effects of Samhwangsasimtang aqua-acupuncture. J Korean Inst Herbal-Acupuncture 2005, 8:51-57.

11. Han SJ, Chung MH: Effect of composite preparation of crude drugs on experimentally induced hyperlipemia in rats -Sam Whang Sasim tang and whang Ryun Haedok Tang. Korean J Pharmacognosy 1996, 27:397-407.

12. Wang YS, Lin RT, Cheng HY, Yang SF, Chou WW, Juo SH: Anti-atherogenic effect of San-Huang-Xie-Xin-Tang, a traditional Chinese medicine, in cultured human aortic smooth muscle cells. J Ethnopharmacol 2011, 133(2):442-447.

13. Lo YC, Tsai PL, Huang YB, Shen KP, Tsai YH, Wu YC, Lai YH, Chen IJ: SanHuang-Xie-Xin-Tang reduces lipopolysaccharides-induced hypotension and inflammatory mediators. J Ethnopharmacol 2005, 96(1-2):99-106.

14. Li CY, Hou YC, Lee Chao PD, Shia CS, Hsu IC, Fang SH: Potential ex vivo immunomodulatory effects of San-Huang-Xie-Xin-Tang and its component herbs on mice and humans. J Ethnopharmacol 2010, 127(2):292-298.

15. Kalachniuk LH, Mel'nychuk DO, Kalachniuk HI: The regulation of fatty acid metabolism and other lipid compounds in ruminant animals. Ukrainskii biokhimicheskii zhurnal 2007, 79(1):22-45.

16. Vernon RG: Lipid metabolism in the adipose tissue of ruminant animals. Prog Lipid Res 1980, 19(1-2):23-106.

17. Jeong HJ, Park SB, Kim S, Kim HK: Total polyphenol content and antioxidative activity of wild grape (Vitis coignetiae) extracts depending on ethanol concentrations. J Korean Soc Food Sci Nutr 2007, 36:1491-1496.

18. Sung HS, Yang CB: Effect of ethanol concentration on saponin composition of red ginseng extract. J Korean Assoc Food Soc 1985, 17:0367-6293.

19. Kim K, Cha M, Lee S, Yoon Y: A study on the inhibitory effects of scutellariae radix on fat accumulation. Korean J Orient Med 2003, 9:45-54

20. Kim NM, Kim YH: Effect of ethanol concentration on extraction of volatile components in cinnamon. Korean J Food Nutr 2000, 13:45-52.

21. Anstee QM, Goldin RD: Mouse models in non-alcoholic fatty liver disease and steatohepatitis research. Int J Exp Pathol 2006, 87(1):1-16.

22. Zheng S, Hoos L, Cook J, Tetzloff G, Davis H Jr, van Heek M, Hwa JJ: Ezetimibe improves high fat and cholesterol diet-induced non-alcoholic fatty liver disease in mice. Eur J Pharmacol 2008, 584(1):118-124.

23. Bjornsson E, Angulo P: Non-alcoholic fatty liver disease. Scand J Gastroenterol 2007, 42(9):1023-1030.

24. Adams LA, Angulo P: Recent concepts in non-alcoholic fatty liver disease. Diabet Med 2005, 22(9):1129-1133.

25. Kumari CS, Govindasamy S, Sukumar E: Lipid lowering activity of Eclipta prostrata in experimental hyperlipidemia. J Ethnopharmacol 2006, 105(3):332-335.

26. Liang $Y T$, Wong WT, Guan L, Tian XY, Ma KY, Huang Y, Chen ZY: Effect of phytosterols and their oxidation products on lipoprotein profiles and vascular function in hamster fed a high cholesterol diet. Atherosclerosis 2011, 219(1):124-133.

27. Zhao C, Dahlman-Wright K: Liver $\mathrm{X}$ receptor in cholesterol metabolism. J Endocrinol 2010, 204(3):233-240.

28. Yang ZH, Miyahara H, Takeo J, Hatanaka A, Katayama M: Pollock oil supplementation modulates hyperlipidemia and ameliorates hepatic steatosis in mice fed a high-fat diet. Lipids Health Dis 2011, 10:189.

29. Sparks DL, Kuo YM, Roher A, Martin T, Lukas RJ: Alterations of Alzheimer's disease in the cholesterol-fed rabbit, including vascular inflammation. Preliminary observations. Ann N Y Acad Sci 2000, 903:335-344.

30. Verhamme P, Quarck R, Hao H, Knaapen M, Dymarkowski S, Bernar H, Van Cleemput J, Janssens S, Vermylen J, Gabbiani G, et al: Dietary cholesterol withdrawal reduces vascular inflammation and induces coronary plaque stabilization in miniature pigs. Cardiovasc Res 2002, 56(1):135-144.

31. Kim SJ, Park JH, Kim KH, Lee WR, Kim KS, Park KK: Melittin inhibits atherosclerosis in LPS/high-fat treated mice through atheroprotective actions. J Atheroscler Thromb 2011, 18(12):1117-1126.

32. Pu P, Wang XA, Salim M, Zhu LH, Wang L, Chen KJ, Xiao JF, Deng W, Shi $\mathrm{HW}$, Jiang $\mathrm{H}$, et al: Baicalein, a natural product, selectively activating AMPKalpha(2) and ameliorates metabolic disorder in diet-induced mice. Mol Cell Endocrinol 2012, 362(1-2):128-138.

33. Bak EJ, Kim J, Choi YH, Kim JH, Lee DE, Woo GH, Cha JH, Yoo YJ: Wogonin ameliorates hyperglycemia and dyslipidemia via PPARalpha activation in db/db mice. Clin Nutr 2013. doi:10.1016/j.cInu.2013.03.013.

34. Zhao HL, Sui Y, Qiao CF, Yip KY, Leung RK, Tsui SK, Lee HM, Wong HK, Zhu $X$, Siu JJ, et al: Sustained antidiabetic effects of a berberine-containing
Chinese herbal medicine through regulation of hepatic gene expression. Diabetes 2012, 61(4):933-943.

35. Qi Q, Peng J, Liu W, You Q, Yang Y, Lu N, Wang G, Guo Q: Toxicological studies of wogonin in experimental animals. Phytother Res 2009, 23(3):417-422.

36. Wang JX, Fan YB, Gao Y, Hu QH, Wang TC: TiO2 nanoparticles translocation and potential toxicological effect in rats after intraarticular injection. Biomaterials 2009, 30(27):4590-4600.

doi:10.1186/1472-6882-13-366

Cite this article as: Ahn et al:: Protective effect of Sam-Hwang-Sa-SimTang against hepatic steatosis in mice fed a high-cholesterol diet. BMC Complementary and Alternative Medicine 2013 13:366.

\section{Submit your next manuscript to BioMed Central and take full advantage of:}

- Convenient online submission

- Thorough peer review

- No space constraints or color figure charges

- Immediate publication on acceptance

- Inclusion in PubMed, CAS, Scopus and Google Scholar

- Research which is freely available for redistribution

Submit your manuscript at www.biomedcentral.com/submit
C BioMed Central 